\title{
Electro-kinetic remediation processes-a brief overview and selected applications
}

\section{Introduction}

In this growing world the need for in-situ remediation has grown importance for various reasons. In-situ remediation is the application of remediation in the subsurface - as compared to ex-situ remediation, which applies to media readily accessible above ground and many times involves excavation and disruption of the soil. Insitu remediation may be applied in the unsaturated/vadoze zone or in saturated soils and groundwater. Anthropogenic activities (municipal and industrial) have resulted in contamination in subsurface soil/ water environment. There are several in-situ remediation methods for example bio-remediation, thermal desorption, soil vapor extraction, and soil flushing just to name a few. The situation where minimal disruption is required or preferred electro-kinetic remediation processes offer a unique solution for organic as well as inorganic pollutants. Electro-kinetic remediation is defined as a technique which uses electric current (DC) to remove pollutants from a medium. It has been effective in removing organic and inorganic contaminants from the soils. ${ }^{1}$

\section{Types of transport mechanisms}

The basic electro-kinetic process is defined by forced/induced movement of target pollutants in soil/sand medium under applied electric field low strength between electrodes of opposite polarities. There are several specific mechanisms that contribute to this movement of pollutants. However, one study suggested that the most important ones are electro-osmosis, electro migration, and electrophoresis. ${ }^{2}$ The electro-osmosis is the movement of pore water from the anode to the cathode in a fluid conduit of small size. The small size of conduits enables electrical double layers of small sizes to be effective in inducing the motion. As the conduit size gets bigger the effectiveness of electro-osmosis rapidly decreases. It is the most effective in pores and capillary tubes. The electro migration is the transport of ions and any other charged species occurring in the applied electric field due to the induced attraction and repulsion forces acting in the electric field. The electro migration is utilized for supply or extraction of ions from various porous materials within both civil and environmental engineering. In civil engineering, most research has been conducted on the removal of chlorides from concrete to hinder reinforcement corrosion $^{3}$ and in many other cases in making concrete denser and stronger, ${ }^{4}$ while in environmental engineering it has been mainly used for remediation of soil contaminated with heavy metals. Whereas, the electrophoresis is the transport of charged particles of colloidal size and bound contaminants due to the application of a low direct current or voltage gradient relative to the stationary pore fluid. Compared to electro migration and electro-osmosis, mass transport by electrophoresis is negligible in soil systems of low permeability such as clay, silty-clay and clay-loam. However, mass transport by electrophoresis may become significant in soil suspension systems and it is the mechanism for the transportation of colloids (including bacteria) and micelles. Electro-osmosis and electro-migration mainly depends on the $\mathrm{pH}$, electric potential applied, and ionic strength.

\author{
Volume 4 Issue I - 2018
}

Chandra M Tummala, Sanjay Tewari

College of Engineering and Science, Louisiana Tech University, USA

Correspondence: Sanjay Tewari, Assistant Professor of Civil Engineering, College of Engineering and Science, Louisiana Tech University, BOGH250, 600 Dan Reneau Dr, PO Box 10348, Ruston, LA 7|272, USA, Email stewari@latech.edu

Received: October 08, 2017| Published: February 09, 2018

The $\mathrm{H}^{+}$and $\mathrm{OH}^{-}$are generated due the electrolysis reaction near the anodes and cathodes. Following basic reactions demonstration the basic chemistry involved.

$$
\begin{aligned}
& \mathrm{H}_{2} \mathrm{O} \leftrightarrow \frac{1}{2} \mathrm{O}_{2}+2 \mathrm{H}^{+}+2 \mathrm{e}^{-} \\
& 2 \mathrm{H}_{2} \mathrm{O}+2 \mathrm{e}^{-} \leftrightarrow \mathrm{H}_{2}+2 \mathrm{OH}^{-}
\end{aligned}
$$

When generated $\mathrm{H}^{+}$and $\mathrm{OH}^{-}$move towards the oppositely charged electrodes, they produce acidic and basic environments near the cathode and the anode respectively. The $\mathrm{pH}$ is a crucial factor that controls various phenomena that occur during the electro-kinetic remediation. ${ }^{5}$ Therefore, the $\mathrm{pH}$ should be carefully monitored during the entire remediation process. After the electro-kinetic remediation process, the positively charged species may be deposited at the anode or may remain in the electrolyte solution and they can be removed by ion exchange columns and chemical precipitation as needed. ${ }^{6}$

\section{Parameters affecting the electro-kinetic processes}

There are many factors that affect electro-kinetic processes. Some of the parameters that play important roles are electrolyte composition, ionic strength, $\mathrm{pH}$, electrical conductivity and field strength, zeta potential, soil chemistry, soil types, permeability, water content, nature of arrangement of electrodes, and material of electrodes.

\section{Some of the specific applications of electro- kinetic processes}

\section{Reversible electro kinetic adsorption barrier}

The use reversible electro-kinetic absorption barriers can give removal efficiency up to $90 \%$ when used against the low solubility contaminants like atrazine and oxyfluorfe. ${ }^{7}$ The removal of organic contaminants can be achieved by the combination of electro-kinetics and other remediation techniques such as chemical oxidation/ reduction, permeable reactive barriers, electrolytic reactive barriers or thermal treatment. 


\section{Electro-kinetic remediation with the addition of surfactants}

One group of scholars explained the importance of addition of surfactants and organo acids sequentially to remove heavy metals from low permeable soils. ${ }^{8}$ According to this study the sequential use of 5\% Igepal CA-720 followed by $1 \mathrm{M}$ citric acid may be an effective remedial strategy to remove coexisting heavy metals and PAHs from clayey soils.

\section{Electro-kinetics with chemical oxidation process}

In one of the studies electro-kinetics was integrated with chemical oxidation process to remediate the creosote-contaminated clay. ${ }^{9}$ The results showed that the integration technique gave better results than the electro-kinetic remediation alone. The elemental analyses showed that the reduction in the natural aluminum and calcium concentrations, increase in zinc, copper, phosphorus and sulfur concentrations, and transfer of several metal cations towards the cathode. Thus, this technology can be a very attractive solution for the degradation of complex organic contaminants into soil. This technology does not generate waste effluents with harmful compounds because they are destroyed into the soil.

\section{Bioelectroremediation}

The combination of electro kinetic remediation with bioremediation has shown some interesting results. The application of an electric field to a polluted site helps in the mobilization of the contaminants and makes them available for the microorganisms. At the same time, soil bacteria are like a colloid with a surface charge. So, they can be moved under the effect of the electric field. Even though the technique has some issues such availability of the availability of suitable bacteria and time needed for effective remediation, this process gave promising results. One study states, through electro bioremediation process, bacteria can transported through a long distances deep into the soil and they can give good results in terms of the remediation. ${ }^{10}$

\section{Electro-heating}

The removal of volatile and semi-volatile organics from soil can be achieved by heating the soil and evaporating the volatile organics and aspirating the vapors, which in turn are trapped in the appropriate absorbent such as active carbon. It is recommended to avoid the use of electro-heating in saturated soils. A soil saturated in moisture favors the transportation of current instead of the electro-heating. Remediation of soil contamination can be a long and costly operation. It has been demonstrated that heating the soil can greatly accelerate the removal of many contaminants, such as gasoline and other volatile organic compounds. Electrical heating is a viable thermal method for removing contaminants from soil. The results showed that at the points where the temperature is more than $40^{\circ} \mathrm{C}, 95 \%$ of the contaminants are removed by vapor extraction method. ${ }^{11}$

The electro-kinetic processes have been applied in many different and complex situations from small scale to large scale remediation projects. The recent research has helped in greater understanding of fundamental mechanisms and applicability towards in-situ remediation challenges of complex nature. However, more research emphasis is needed in dealing with emerging contaminants in soil/ water complex medium.

\section{Acknowledgments}

None.

\section{Conflicts of interest}

The authors declare there is no conflict of interest.

\section{Funding}

None.

\section{References}

1. Acar YB, Gale RJ, Alshawabkeh AN, et al. Electrokinetic remediation: basics and technology status. Journal of hazardous materials. 1995;40(2):117-137.

2. Virkutyte J, Sillanpää M, Latostenmaa P. Electrokinetic soil remediationcritical overview. Sci Total Environ. 2002;289(1):97-121.

3. Bertolini L, Elsener B, Pedeferri P, et al. Corrosion of steel in concrete: prevention, diagnosis, repair: John Wiley \& Sons; 2013. p. 434.

4. Cardenas HE, Struble LJ. Electrokinetic nanoparticle treatment of hardened cement paste for reduction of permeability. Journal of materials in civil engineering. 2006;18(4):554-560.

5. López-Vizcaíno R, Yustres A, León MJ, et al. Multiphysics Implementation of Electrokinetic Remediation Models for Natural Soils and Porewaters. Electrochimica Acta. 2017;225:93-104.

6. Acar YB, Alshawabkeh. Principles of electrokinetic remediation. Environmental science \& technology. 1993;27(13):2638-2647.

7. Dos Santos EV, Sáez C, Cañizares P, et al. Reversible electrokinetic adsorption barriers for the removal of atrazine and oxyfluorfen from spiked soils. Journal of hazardous materials. 2017;322:413-420.

8. Reddy KR, Maturi K, Cameselle C. Sequential electrokinetic remediation of mixed contaminants in low permeability soils. Journal of Environmental Engineering. 2009;135(10):989-998.

9. Isosaari P, Piskonen R, Ojala P, et al. Integration of electrokinetics and chemical oxidation for the remediation of creosote-contaminated clay. $J$ Hazard Mater. 2007;144(1):538-548.

10. Wick LY, Shi L, Harms H. Electro-bioremediation of hydrophobic organic soil-contaminants: A review of fundamental interactions. Electrochimica Acta. 2007;52(10):3441-3448.

11. Vermeulen F, McGee B. In-situ electromagnetic heating for hydrocarbon recovery and environmental remediation. Journal of Canadian Petroleum Technology. 2000;39(08). 